\title{
Acute Heart Failure Comorbidome: The Impact of Everything Else
}

\section{Comorbidoma na Insuficiência Cardíaca Aguda: O Impacto de Tudo o Resto}

\author{
Mariana Alves MEIRELES ${ }^{1}$, João GONÇALVES ${ }^{1}$, João NEVES ${ }^{1}$ \\ Acta Med Port 2020 Feb;33(2):109-115 - https://doi.org/10.20344/amp.11051
}

\section{ABSTRACT}

Introduction: Heart failure frequently coexists with several comorbidities. Our aim is to evaluate the prognostic role of various comorbidities in the risk of acute heart failure development.

Material and Methods: Comorbidities of patients with acute heart failure were, retrospectively, compared to a control group of patients with chronic heart failure admitted to an Internal Medicine unit in a 2-year period. Logistic regression models were constructed to determine their association with acute heart failure and to develop a comorbidome.

Results: We identified 229 patients with acute heart failure and 201 patients with chronic heart failure. Age and female gender were higher in acute heart failure group $(p<0.001)$ as was the number of comorbidities $(4.0 \pm 3.0$ vs $4.0 \pm 2.0, p=0.044)$. Hyperuricemia (odds ratio 2.46, confidence interval 95\% $1.41-4.31, p=0.002$ ), obesity (odds ratio 2.22 , confidence interval $95 \% 1.31-3.76, p=$ 0.003 ), atrial fibrillation (odds ratio 1.93, confidence interval 95\% $1.31-2.87, p=0.001$ ), peripheral artery disease (odds ratio 2.12 , confidence interval 95\% $1.01-4.42, p=0.046$ ) and chronic kidney disease (odds ratio 2.47 , confidence interval $95 \% 1.65-3.71, p<$ 0.001 ) were associated with acute heart failure. Obesity, atrial fibrillation, peripheral artery disease and chronic kidney disease were identified as independent risk factors. Patients with multiple comorbidities had a superior risk of hospitalization due to heart failure: zero comorbidities - odds ratio $0.43,95 \%$ confidence interval $0.28-0.67, p<0.001$; one comorbidity - odds ratio 0.69 , 95\% confidence interval $0.47-1.01, p=0.057$; two comorbidities - odds ratio $1.85,95 \%$ confidence interval $1.11-3.08, p=0.019$; $\geq$ three comorbidities - odds ratio $5.81,95 \%$ confidence interval $2.77-12.16, p<0.001$.

Discussion: This study shows an association between several comorbidities and hospital admission due to acute heart failure. The association seems to strengthen in the presence of multiple comorbidities.

Conclusion: A comorbidome is a useful tool to identify comorbidities associated with higher risk of acute heart failure. The identification of vulnerable patients may allow multidimensional interventions to minimize future hospital admissions.

Keywords: Heart Failure; Hospitalization; Comorbidity; Mortality

\section{RESUMO}

Introdução: A insuficiência cardíaca frequentemente coexiste com diversas comorbilidades. O nosso objetivo é avaliar o valor prognóstico de diferentes comorbilidades no risco de desenvolvimento de insuficiência cardíaca aguda.

Material e Métodos: As comorbilidades dos doentes com insuficiência cardíaca aguda foram, retrospetivamente, comparadas com um grupo controlo de doentes com insuficiência cardíaca crónica admitidos numa unidade de Medicina Interna no período de dois anos. Modelos de regressão logística foram construídos para determinar as comorbilidades associadas a insuficiência cardíaca aguda e para a construção do comorbidoma.

Resultados: Foram identificados 229 doentes com insuficiência cardíaca aguda e 201 com insuficiência cardíaca crónica. A idade e género feminino foram superiores no grupo insuficiência cardíaca aguda $(p<0,001)$, tal como o número de comorbilidades $(4,0 \pm$ 3,0 vs $4,0 \pm 2,0, p=0,044$ ). A hiperuricemia (odds ratio 2,46, intervalo confiança 95\% 1,41-4,31, $p=0,002$ ), a obesidade (odds ratio 2,22 , intervalo confiança $95 \% 1,31-3,76, p=0,003$ ), a fibrilação auricular (odds ratio 1,93, intervalo confiança 95\% 1,31 - 2,87, $p=$ 0,001 ), a doença arterial periférica (odds ratio 2,12, intervalo confiança 95\% 1,01-4,42, $p=0,046$ ) e a doença renal crónica (odds ratio 2,47, intervalo confiança $95 \% 1,65-3,71, p<0,001$ ) associaram-se com a insuficiência cardíaca aguda. A obesidade, a fibrilação auricular, a doença arterial periférica e a doença renal crónica foram identificadas como fatores de risco independentes. Doentes com múltiplas comorbilidades tiveram um risco superior de hospitalização por insuficiência cardíaca: zero comorbilidades - odds ratio 0,43 , $95 \%$ intervalo confiança $0,28-0,67, p<0,001$; uma comorbilidade - odds ratio $0,69,95 \%$ intervalo confiança $0,47-1,01, p=0,057$ duas comorbilidades - odds ratio 1,85, 95\% intervalo confiança $1,11-3,08, p=0,019$; $\geq$ três comorbilidades - odds ratio $5,81,95 \%$ intervalo confiança $2,77-12,16, p<0,001$.

Discussão: Este estudo mostra uma associação entre várias comorbilidades e a hospitalização por insuficiência cardíaca aguda. A associação parece fortalecer-se na presença de múltiplas comorbilidades.

Conclusão: O comorbidoma é uma ferramenta útil para identificar comorbilidades associadas a maior risco de insuficiência cardíaca aguda. A identificação de doentes vulneráveis pode permitir a instituição de intervenções multidimensionais para minimizar hospitalizações futuras.

Palavras-chave: Comorbilidade; Hospitalização; Insuficiência Cardíaca; Mortalidade

\section{INTRODUCTION}

The incidence of heart failure (HF) has remained stable over the past two decades while survival has improved. ${ }^{1-3}$ It is estimated that at 45 years, the lifetime risk for HF, at

age 75 and 95 , ranges from $20 \%-30 \%$ and $39 \%-46 \%$, respectively. ${ }^{4}$ In Portugal, the age adjusted prevalence of HF varies between $1.4 \%$ and $16.1 \%{ }^{5}$ with an expected increase

1. Internal Medicine Department. Centro Hospitalar do Porto. Porto. Portugal.

$\square$ Autor correspondente: Mariana Alves Meireles. mra.meireles@gmail.com

Recebido:10 de julho de 2018 - Aceite: 26 de agosto de 2019 | Copyright @ Ordem dos Médicos 2020 
of $30 \%$ by 2035 and $33 \%$ by $2060 .{ }^{6}$

Acute HF (aHF) is responsible for nearly one million hospitalizations each year with rising rates $^{7}$ and, after an initial hospitalization, $25 \%$ of patients are readmitted at 30 days, $35 \%$ of which due to a new exacerbation. ${ }^{8}$ Improvements in treatments have improved survival and reduced the hospitalization rate in patients with aHF, although the outcome remains unsatisfactory. ${ }^{16}$ Moreover, HF care constitutes an increasing economic burden, mainly due to costs related to hospitalizations. ${ }^{9}$

Whilst the differentiation of the underlying cause of heart disease and identification of precipitating factors of aHF are extremely important, identification and management of associated comorbidities may have an influence in the outcomes. In elderly patients with HF, the prevalence of comorbidities can reach $96 \% .{ }^{10}$ Those with multiple comorbidities are often older and have a higher New York Heart Association (NYHA) class. Several studies have suggested that comorbidities have a significant prognostic role as some of them are predictive of mortality and hospitalization..$^{9,10}$

aHF is one of the most common diagnoses in patients admitted to Internal Medicine departments, ${ }^{11}$ where multimorbid patients are extremely prevalent. Only few studies have analysed multiple non-cardiac comorbidities in patients with HF, a minority of which assessed patients admitted to Internal Medicine units. ${ }^{12,13}$ Our aim is to evaluate the role of comorbidities in patients with aHF in an Internal Medicine unit.

\section{MATERIAL AND METHODS}

This study was conducted as a retrospective cohort study. A sample of consecutive patients admitted to an Internal Medicine ward of a tertiary institution (Porto Hospital Medical Centre - Porto - Portugal), in the period 2014 - 2015, was selected. HF diagnosis was presumed after medical records review for symptoms, natriuretic peptide levels and echocardiographic findings according to European Society of Cardiology guidelines. ${ }^{14}$ Patients without an echocardiogram were included if relevant heart disease was mentioned in their clinical record and NT-proBNP levels were higher than $1000 \mathrm{pg} / \mathrm{mL}$.

Subjects with aHF and chronic heart failure (cHF) were included, regardless if the former was the main diagnosis or an associated disease. aHF included acute, de novo and chronic decompensated HF and was presumed in the presence of at least two clinical criteria of aggravated peripheral or central congestion (dyspnoea, orthopnoea, paroxysmal nocturnal dyspnoea, venous jugular distension, rales, peripheral oedema, ascites), developed in the last weeks. cHF was presumed in those patients admitted for reasons other than aHF and in the presence of the chronic symptoms stated above or, in its absence, if there was history of HF controlled by appropriate therapy. Patients younger than 18 years were excluded.

Demographic data (age and sex), length of stay (measured in days), number of diagnoses at discharge (codified according to ICD-9), outcomes (in-hospital mortality and readmission at 30 days), heart disease characterization (aetiology and left ventricle ejection fraction) and comorbidities were collected using electronic medical records. Fifteen comorbidities were considered: diabetes, dyslipidaemia, hypertension, hyperuricemia, obesity, atrial fibrillation (AF), peripheral arterial disease (PAD), cerebral vascular disease (CVD), pulmonary thromboembolism (PE), chronic kidney disease (CKD), anaemia, chronic obstructive pulmonary disease (COPD), asthma, obstructive sleep apnea-hypopnea syndrome (OSAHS) and dementia. Comorbidities were considered if the diagnostic criteria listed in international guidelines were met after review of physical examination records, blood tests, ECG, lung and sleep function tests, doppler ultrasound, cognitive tests and/or previous convincing record of the disease. ${ }^{14,15} \mathrm{CKD}$ was defined as stage 3 - $5 \mathrm{KDIGO}$ and glomerular filtration rate was calculated using the basal creatinine level before admission.

Reduced left ventricle ejection fraction was presumed if below $40 \%$, according to the European Society of Cardio$\log .^{16}$

Demographic variables and comorbidities of patients with aHF were compared to those of patients with cHF admitted for other reasons. We considered only comorbidities with a prevalence $>10 \%$. Prolonged hospital stay was presumed if above the median length of stay of Internal Medicine department in 2014-2015.

Baseline continuous data was presented as median \pm interquartile range (IQR). Categorical data was presented as absolute and relative frequencies. Patients with aHF and cHF were compared using unpaired t-test, Mann-Whitney test or chi-squared test depending on data type. Uni and multivariate logistic regression analyses (adjusted for age and gender) were used to estimate the odds ratio (OR) and $95 \%$ confidence interval $(\mathrm{Cl})$ of each comorbidity. Results are visualized as a comorbidome, a graphical representation of the prevalence of comorbidities and their association with the outcome.

A two-tailed $p$ value of less than 0.05 was considered significant. Statistical analysis was performed with IBM SPSS Statistical Software, version 24.0.

The ethics committee of our Hospital centre approved this study.

\section{RESULTS}

Of a sample of 839 patients admitted to an Internal Medicine unit, 430 patients had HF. Compared to the non-HF population, patients were significantly older and more frequently female. Length of stay was $8.5 \pm 9.0$ days in the HF group and $9.0 \pm 11$ in the non-HF group $(p=0.094)$. HF patients had a higher number of diagnoses at discharge (15.0 \pm 5 vs $9.0 \pm 6.0, p<0.001$ ), as well as more cardiovascular risk factors $(2.0 \pm 2.0$ vs $.1 .0 \pm 2.0, p<0.001)$.

Two hundred and twenty-nine patients were diagnosed with aHF and 201 with cHF. The demographic and baseline characteristics are summarized in Table 1 . Those with aHF were older (OR 1.04, 95\% Cl $1.02-1.05, p<0.001)$ and more often female (OR 2.16, 95\% Cl $1.46-3.19, p<0.001$ ). 
Table 1 - Baseline characteristics

\begin{tabular}{|c|c|c|c|}
\hline & Acute heart failure & Chronic heart failure & $p$ \\
\hline \multicolumn{4}{|l|}{ Demographics } \\
\hline Age (years), median (IQR) & $81.0(13.0)$ & $70.0(25.0)$ & $<0.001^{\dagger}$ \\
\hline Female sex, $\mathrm{n}(\%)$ & $154(67.2)$ & $103(48.8)$ & $<0.001^{*}$ \\
\hline Number of diagnoses, median (IQR) & $15.0(6.0)$ & $14.5(6.0)$ & $0.065^{\dagger}$ \\
\hline \multicolumn{4}{|l|}{ Cardiac disease } \\
\hline Ischemic heart disease, $\mathrm{n}(\%)$ & $78(34.1)$ & $54(26.9)$ & $0.134^{*}$ \\
\hline Hypertensive heart disease, n (\%) & $127(55.5)$ & $118(58.7)$ & $0.319^{*}$ \\
\hline Valvular heart disease, $\mathrm{n}(\%)$ & $64(27.9)$ & $39(19.4)$ & $0.035^{*}$ \\
\hline Left ventricle ejection fraction $<40 \%, \mathrm{n}(\%)$ & $62(34.4)$ & $22(15.7)$ & $<0.001^{*}$ \\
\hline
\end{tabular}

IQR: interquartile range; *: chi-squared test; †: Mann- Whitney $U$ test.

The most common clinical hemodynamic profile was B (wet and dry) (96\%). Hypertensive heart disease was the most frequent aetiology, followed by ischemic and valvular heart diseases. Valvular heart disease was associated with aHF (OR 1.61, 95\% Cl 1.02 - 2.54, $p=0.038$ ). Echocardiogram was available in 320 patients. Reduced left ventricle ejection fraction was observed in $26.3 \%$ and was significantly associated with aHF (OR 2.82, 95\% Cl $1.63-4.88, p<$ 0.001).

The number of total diagnoses at discharge was higher in aHF patients although without statistical significance $(15.0 \pm 6.0$ vs $14.5 \pm 6.0, p=0.065)$. A total of 15 comorbidities were searched in this cohort and $91.6 \%$ of patients had at least one. The median number of comorbidities was 4.0 \pm 3.0 (range 0 - 11) per subject for the whole cohort and higher in patients with aHF compared with patients with $\mathrm{cHF}$ $(4.0 \pm 3.0$ vs $4.0 \pm 2.0$, respectively; $p=0.044)$. Twelve of these comorbidities were included in the analysis as asthma $(5.1 \%)$, OSAHS (5.3\%) and PE $(2.8 \%)$ were excluded by the low prevalence. Table 2 summarizes the prevalence of comorbidities in aHF patients. Cardiovascular risk factors were common, particularly hypertension (80\%), followed by diabetes (51.1\%) and dyslipidaemia (48.5\%). AF, CKD and anaemia were present in approximately $50 \%$ of those with

Table 2 - Prevalence of comorbidities in acute heart failure patients

\begin{tabular}{lc}
\hline & $\begin{array}{c}\text { Prevalence } \\
\mathrm{n}(\%)\end{array}$ \\
\hline Hypertension, $\mathrm{n}(\%)$ & $184(80.3)$ \\
Diabetes, $\mathrm{n}(\%)$ & $117(51.1)$ \\
Dyslipidemia, $\mathrm{n}(\%)$ & $111(48.5)$ \\
Atrial fibrillation, $\mathrm{n}(\%)$ & $110(48.0)$ \\
Chronic renal failure, $\mathrm{n}(\%)$ & $109(47.6)$ \\
Anaemia, $\mathrm{n}(\%)$ & $103(45.0)$ \\
Obesity, $\mathrm{n}(\%)$ & $53(23.1)$ \\
Hyperuricemia, $\mathrm{n}(\%)$ & $49(21.4)$ \\
Dementia, $\mathrm{n}(\%)$ & $46(20.1)$ \\
Cerebrovascular disease, $\mathrm{n}(\%)$ & $42(18.3)$ \\
Peripheral artery disease, $\mathrm{n}(\%)$ & $25(10.9)$ \\
CoPD, $\mathrm{n}(\%)$ & $24(10.5)$ \\
\hline
\end{tabular}

COPD: chronic obstructive pulmonary disease
aHF patients. Respiratory diseases were recorded in 52 cases $(22.7 \%)$, mainly COPD $(10.5 \%)$. The strength of the association between the 12 comorbidities and the admission due to aHF (vs admission due to non-aHF reasons) are presented in Table 3 and Fig. 1 as an orbital bubble chart.

Of all comorbidities, obesity, AF, PAD and CKD were independently associated with admission due to aHF when adjusted for sex, age and other comorbidities. The strength of the association, in hospitalized patients, increased with the number of comorbidities: 0 comorbidities - OR 0.43 , $95 \% \mathrm{Cl} 0.28-0.67, p<0.001 ; 1$ comorbidity - OR 0.69 , $95 \%$ Cl $0.47-1.01, p=0.057 ; 2$ comorbidities - OR 1.85, $95 \% \mathrm{Cl} 1.11-3.08, p=0.019 ; \geq 3$ comorbidities - OR 5.81, $95 \%$ Cl $2.77-12.16, p<0.001$.

\section{DISCUSSION}

This study shows that HF is a prevalent diagnosis amongst patients admitted to an Internal Medicine department, coexisting in more than $50 \%$. Almost half of those have some degree of decompensation during hospitalization. Previous studies, conducted in Internal Medicine departments, have demonstrated that HF is the primary diagnosis in $3.1 \%$ of the first admissions, a percentage which increases up to $8.7 \%$ for patients with multiple hospital readmissions. ${ }^{17}$ In the PRECIC study, a cohort of 3746 hospitalized patients in a Portuguese Internal Medicine ward, $16.7 \%$ had a HF code in the discharge summaries and in $11.5 \%$ aHF was the main diagnosis. ${ }^{18}$ The prevalence of HF is expected to increase $17 \%$ between 2018 and $2035 .{ }^{6}$

When considering all the diagnoses at discharge, heart diseases represent $37.4 \% .{ }^{11}$ Compared to multiple previously conducted studies, our patients are almost a decade older $^{19-21}$ and the number of total diagnoses at discharge was higher. ${ }^{11}$ Our sample is, therefore, representative of the high prevalence of HF and comorbidities in patients admitted to Internal Medicine departments.

There was a higher proportion of older and female patients in the aHF group. It is well known that among patients with aHF there are significant differences in comorbidities, precipitating factors and predictors of in-hospital mortality between genders. ${ }^{20}$ Nowadays, more than $50 \%$ of HF patients have preserved left ventricle ejection fraction ( $p E F$ ) with a number of community-based studies showing and 
Table 3 - Association between comorbidities and acute heart failure

\begin{tabular}{lcccc}
\hline & Univariate & & \multicolumn{2}{c}{ Multivariate } \\
& OR $(95 \% \mathrm{Cl})$ & $\boldsymbol{p}$ & OR $(95 \% \mathrm{Cl})$ & $\boldsymbol{p}$ \\
\hline Hypertension & $1.21(0.76-1.93)$ & $0.413^{*}$ & $0.74(0.43-1.30)$ & $0.294^{\dagger}$ \\
Diabetes & $1.29(0.88-1.88)$ & $0.191^{*}$ & $1.06(0.67-1.67)$ & $0.814^{\dagger}$ \\
Dyslipidemia & $0.97(0.66-1.42)$ & $0.871^{*}$ & $0.69(0.44-1.10)$ & $0.112^{\dagger}$ \\
Atrial fibrillation & $1.93(1.31-2.87)$ & $0.001^{*}$ & $1.69(1.08-2.62)$ & $0.021^{\dagger}$ \\
Chronic kidney disease & $2.47(1.65-3.71)$ & $<0.001^{*}$ & $1.66(1.04-2.66)$ & $0.035^{\dagger}$ \\
Anaemia & $1.15(0.79-1.69)$ & $0.468^{*}$ & $0.98(0.63-1.53)$ & $0.919^{\dagger}$ \\
Obesity & $2.22(1.31-3.76)$ & $0.003^{*}$ & $2.57(1.38-4.79)$ & $0.003^{\dagger}$ \\
Hyperuricemia & $2.46(1.41-4.31)$ & $0.002^{*}$ & $1.76(0.92-3.35)$ & $0.089^{\dagger}$ \\
Dementia & $0.55(0.36-0.86)$ & $0.008^{*}$ & $0.38(0.22-0.64)$ & $0.001^{\dagger}$ \\
Cerebrovascular disease & $0.61(0.39-0.97)$ & $0.035^{*}$ & $0.62(0.37-1.05)$ & $0.074^{\dagger}$ \\
Peripheral artery disease & $2.12(1.01-4.42)$ & $0.046^{*}$ & $3.12(1.35-7.22)$ & $0.008^{\dagger}$ \\
COPD & $0.62(0.35-1.09)$ & $0.097^{*}$ & $0.78(0.40-1.52)$ & $0.466^{\dagger}$ \\
\hline
\end{tabular}

COPD: chronic obstructive pulmonary disease; Cl: confidence interval; *: chi-squared test; $\uparrow$ : logistic regression

increasing prevalence. ${ }^{23}$ Patients with older age, female sex and additional comorbidities are at an increased risk of pEF. ${ }^{24}$ Our study mirrors this reality which is not surprising considering the older age, proportion of female patients and high burden of comorbidities.

According to multiple registries, aHF patients have a constellation of cardiovascular and non-cardiovascular comorbidities. ${ }^{18}$ It is estimated that $36 \%-42 \%$ of the Portuguese population has hypertension. ${ }^{26-28}$ In our cohort, hypertension was the most prevalent risk factor $(80 \%)$, similar to other studies conducted in aHF. ${ }^{29}$

AF is recognised as a significant comorbidity with the prevalence ranging from $24 \%-44 \%{ }^{25}$ The prevalence of $\mathrm{AF}$ increases with age and is particularly frequent in hypertensive and HF patients. In Internal Medicine departments, the prevalence can be as high as $50 \%,{ }^{11}$ as observed in our cohort. AF is both a cause and consequence of HF, with complex interactions leading to the impairment of systolic and diastolic function that is not present in patients with sinus rhythm. In the literature, AF is associated with a threefold increased risk of incident HF, stroke and all-cause of death, especially in women. ${ }^{30}$ We found that AF has a strong association with aHF with a persistent impact when adjusted for age, gender and other comorbidities.

Data suggests that non-cardiovascular comorbidities are present in more than $30 \%$ of patients with HF. ${ }^{19,31}$ In a Medicare study, nearly $40 \%$ of elderly patients with HF had 5 or more noncardiac comorbidities and this group accounted for most total hospital days. ${ }^{32}$ Of the non-cardiovascular comorbidities, CKD was present in almost half of the patients and was found to be an independent risk factor for aHF. HF is a known risk factor for renal failure and the same risk factors may contribute to both diseases. The HF Pilot Survey of the EURObservational research programme of the European Society of Cardiology found that CKD was associated with HF hospitalization and $41 \%$ of all-cause -mortality could be attributable to this comorbidity. ${ }^{33}$ Renal dysfunction may represent a barrier for optimal medical treatment for those with $\mathrm{HF}$ and reduced ejection fraction and may limit the clinical response to drugs for the management of congestive symptoms. Early interventions in CKD should be started as soon as possible, especially in patients at high risk of aHF, in the attempt to mitigate this burden.

Cardiovascular risk factors were prevalent, with diabetes and dyslipidaemia affecting almost $50 \%$ of patients. Previous studies state that $27 \%$ to $45 \%$ of aHF patients have diabetes ${ }^{25}$ and these present more frequently with acute pulmonary oedema or acute coronary syndrome. ${ }^{34}$ Diabetes has been described as a risk factor for hospitalization. ${ }^{30,35}$ Interestingly, in this cohort, diabetes was not more frequent in aHF compared to cHF patients.

Hyperuricemia and obesity were the only cardiovascular risk factors associated with aHF. The former has been demonstrated to be independently associated with mortality and correlates with age, male gender, prior diuretic use and renal failure ${ }^{36}$ Hyperuricemia is a marker of abnormal oxidative metabolism and an inflammatory mediator able to disrupt endothelial function and it has been linked to the development of HF. Additionally, diuretics are known to contribute to hyperuricemia. Being the core therapy to HF congestive symptoms, either in aHF or in the prevention of symptoms in stable $\mathrm{cHF}$, it is not unexpected that patients more prone to decompensation had higher uric acid levels.

Obesity is thought to have a complex interplay in the pathophysiology of HF, on left ventricular structure and function and in the presence of other risk factors for HF, including hypertension and coronary artery disease. It is expected an increase in the risk of HF of $5 \%$ for men and $7 \%$ for women for each increment of 1 in body-mass index (BMI). ${ }^{37}$ Although overweight and mildly obese patients consistently have shown the lowest mortality risk of any BMI group, all cause and cardiovascular mortality rates begin to rise for $\mathrm{BMI}>35 \mathrm{~kg} / \mathrm{m}^{2}{ }^{38}$

Interestingly we did not find an association between CVD and aHF. It is known that the risk of recurrent stroke is about two-fold higher in patients with HF and that clinically 


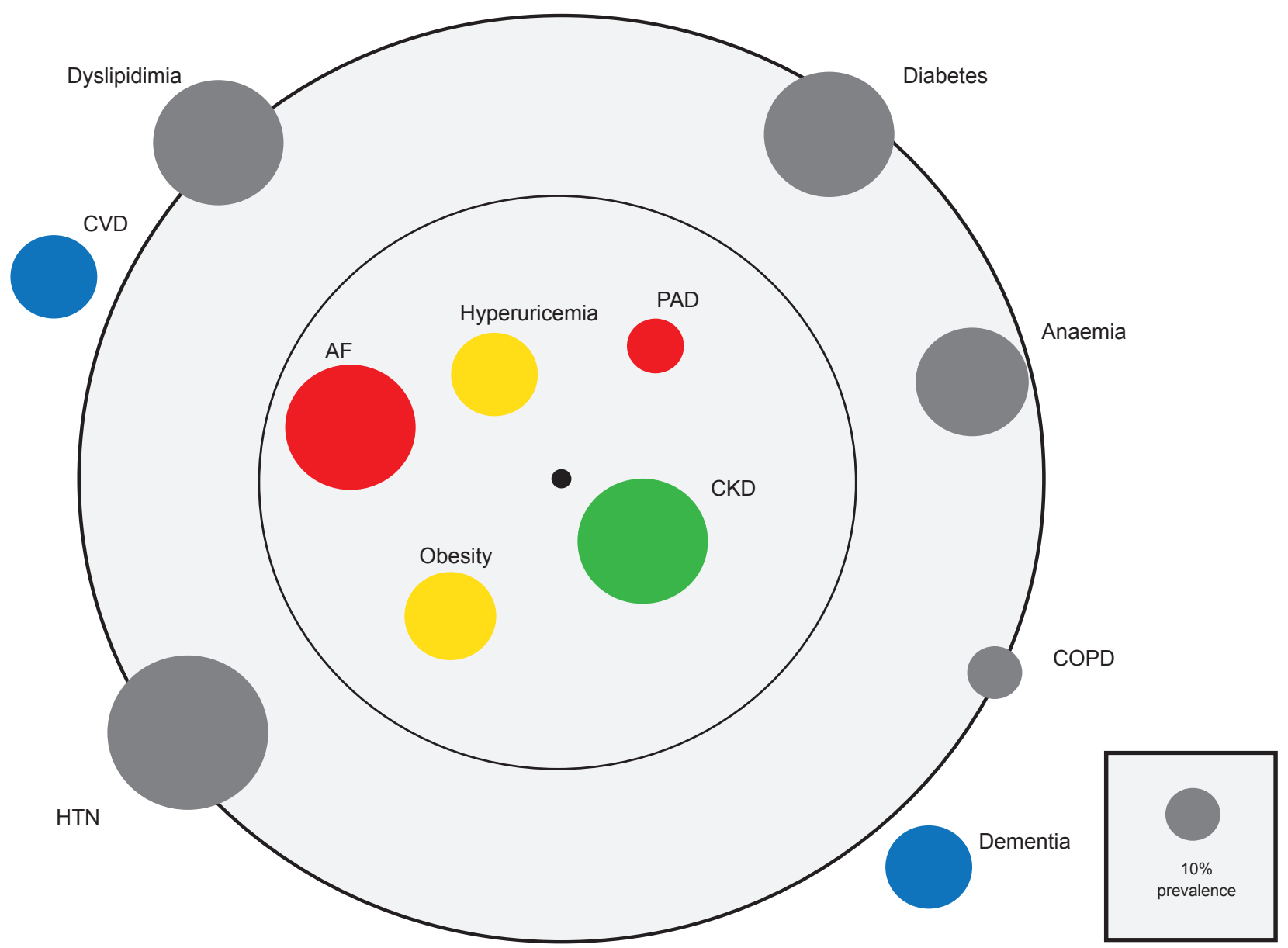

Figure 1 - Comorbidome of acute heart failure patients. Diameter of the circles represents the prevalence of each comorbidity. Proximity to the black centre of the circle represents stronger positive association with acute heart failure. Colourful circles represent positive and negative associations. Comorbidities (bold) within the inner circle are significantly associated with increased risk. Comorbidities within the outer circle are non-significantly associated with risk. Comorbidities outside the outer circle are negatively associated with acute heart failure. OR of univariate analysis was used as the measure of the association.

REF: reduced (left ventricle) ejection fraction; CKD: chronic kidney disease; PAD: peripheral artery disease; Valvular: valvular cardiopathy; AF: atrial fibrillation; HTN: hypertension; COPD: chronic obstructive pulmonary disease; CVD: cerebrovascular disease. Coloured circles represent organ systems (Blue: central nervous system; yellow: vascular risk factor; red: cardiovascular disease; green: renal disease).

asymptomatic ischemic brain lesions are two to four times more likely in HF patients. In turn, $10 \%-24 \%$ of stroke patients have HF. While HF, either by inducing hypoperfusion or as a source of emboli, is an established risk factor for stroke, the reverse is not clear. Despite the shared risk factors for stroke and HF, previous cohorts were also unable to associate previous stroke with HF mortality or readmission risk. $^{32}$

Patients with cHF are at higher risk of developing Alzheimer's disease and vascular dementia, ${ }^{39,40}$ a reality poorly recognized by physicians. ${ }^{41}$ Neuropsychological performance in HF patients is lower compared to control subjects and a pooled analysis showed that the odds ratio for cognitive impairment was $1.62(95 \% \mathrm{Cl} 1.48-1.79, p<0.0001)$ among subjects with HF. Among older patients with $\mathrm{cHF}$, cognitive dysfunction has been associated with an increase in non-therapeutic adherence, hospital admission and a 5-fold increase in mortality risk. ${ }^{42}$ In our analysis, dementia was inversely associated with aHF. The existence of caregivers, in face of patients unable to secure self-care, could be hypothesised as a way to lower non-therapeutic adherence. However, we believe that this inverse association is not necessarily real. The main diagnosis leading to hospital admission in this population was infection and aHF only occurred in $11 \%$ of the demented patients, leading us to the conclusion that this inverse correlation is due to a sampling bias.

Comorbidities influence not only the severity of symptoms and the quality of life, but also the prognosis. It is estimated that $39 \%$ of $\mathrm{HF}$ patients are hospitalized because of non-cardiovascular comorbid conditions. ${ }^{43}$ In this cohort, $46.7 \%$ of cHF patients were admitted for reasons others than aHF. A recent study including 207984 aHF patients showed that $82 \%$ had at least one comorbidity. ${ }^{44}$ These results are in line with our findings. We found that the higher the burden of comorbidities, the higher the association with aHF, with almost a 6 -fold increase in the presence of 3 or more comorbidities. It is already known that patients with higher comorbidity burden have an increased risk of readmission and mortality. ${ }^{44}$ 
$\mathrm{HF}$ is, in fact, a classic example of some potential interactions between several medical conditions. The concept of comorbidome entails a graphic representation of the prevalence and impact of comorbidities in several groups of patients and disease. ${ }^{45}$ This disease clustering approach could lead towards the development of new multimorbidity guidelines. This first HF comorbidome could be the first step in the direction of a multimodal approach for the care of HF patients.

Our study has several limitations. First, this is a retrospective evaluation and future analyses of comorbidities$\mathrm{HF}$ interaction should be conducted prospectively, aiming at a larger sample. Second, aHF was not always the main diagnosis for hospitalization and patients with $\mathrm{cHF}$ are not an ideal control group as they were admitted due to other acute illnesses. The impact of these diseases was not analysed. However, our aim was to compare inpatients of an Internal Medicine department, with and without aHF, and we not only were expecting this influence as we were interested in it. The selection of an Internal Medicine department might also lead to a selection bias and not be generalizable to the global HF population. Third, some of the associations found illustrate the complexity of patients admitted to Internal Medicine departments. We believe that some comorbidities, not shown to be associated with aHF in this study, might indeed be. Future studies should be more robust in order to confirm the the associations found and uncover others. On the other hand, a cause-effect analysis should be pursued in order to achievea better understanding of these interplays. Forth, our data had been extracted from a single tertiary hospital. For this reason, we cannot extrapolate our results to other hospitals with different structure or to other departments such as cardiology or geriatrics.

\section{REFERENCES}

1. McCullough PA, Philbin EF, Spertus JA, Kaatz S, Sandberg KR, Weaver WD. Confirmation of a heart failure epidemic: Findings from the resource utilization among congestive heart failure (reach) study. J Am Coll Cardiol. 2002;39:60-9.

2. Roger VL, Weston SA, Redfield MM, Hellermann-Homan JP, Killian $\mathrm{J}$, Yawn BP, et al. Trends in heart failure incidence and survival in a community-based population. JAMA. 2004;292:344-50.

3. Levy D, Kenchaiah S, Larson MG, Benjamin EJ, Kupka MJ, Ho KK, et al. Long-term trends in the incidence of and survival with heart failure. $\mathrm{N}$ Engl J Med. 2002;347:1397-402.

4. Huffman MD, Berry JD, Ning H, DyerAR, Garside DB, Cai X, et al. Lifetime risk for heart failure among white and black americans: cardiovascular lifetime risk pooling project. J Am Col Cardiol. 2013;61:1510-7.

5. Ceia F, Fonseca C, Mota T, Morais H, Matias F, de Sousa A, et al; EPICA Investigators. Prevalence of chronic heart failure in Southwestern Europe: the EPICA study. Eur J Heart Fail. 2002;4:531-9.

6. Fonseca C, Brás D, Araújo I, Ceia F. Heart failure in numbers: estimates for the 21st century in Portugal. Rev Port Cardiol. 2018;37:97-104.

7. Roger VL. Epidemiology of heart failure. Circ Res. 2013;113:646-59.

8. Dharmarajan K, Hsieh AF, Lin Z, Bueno H, Ross JS, Horwitz LI, et al. Diagnoses and timing of 30-day readmissions after hospitalization for heart failure, acute myocardial infarction, or pneumonia. JAMA. 2013;309:355-63.

9. Dunlay SM, Shah ND, Shi Q, Morlan B, VanHouten H, Long $\mathrm{KH}$, et al. Lifetime costs of medical care after heart failure diagnosis. Circ Cardiovasc Qual Outcomes. 2011;4:68-75.

10. Braunstein JB, Anderson GF, Gerstenblith G, Weller W, Niefeld M, Herbert R, et al. Noncardiac comorbidity increases preventable

\section{CONCLUSION}

Obesity, AF, PAD, CKD were found to be independently associated with aHF. A higher number of comorbidities correlated with aHF admission. Comorbidomes help to phenotype diseases, enhancing unexpected associations and promoting a better understanding about comorbidities and outcomes. Indeed, we believe that a holistic approach of HF patients may stimulate the development of strategies for early intervention on comorbidities in order to prevent rehospitalizations and limit morbidity, mortality and heath care costs.

\section{PROTECTION OF HUMANS AND ANIMALS}

The authors declare that the procedures were followed according to the regulations established by the Clinical Research and Ethics Committee and to the Helsinki Declaration of the World Medical Association.

\section{DATA CONFIDENTIALITY}

The authors declare having followed the protocols in use at their working center regarding patients' data publication.

\section{CONFLICTS OF INTEREST}

The authors declare that there is no conflict of interests regarding the publication of this paper.

\section{FUNDING SOURCES}

This research did not receive any specific grant from funding agencies in the public, commercial, or not-for-profit sectors.

hospitalizations and mortality among Medicare beneficiaries with chronic heart failure. J Am Coll Cardiol. 2003;42:1226-33.

11. Etxeberria-Lekuonaa $D$, Casas Fernández de Tejerinaa JM, Méndez López I, Oteiza Olasoa J, Arteaga Mazuelasb M, Jarne Betran V. Multiple hospitalizations at the Department of Internal Medicine of a tertiary hospital. Rev Clin Esp. 2015;215:9-17.

12. Martínez F, Martínez-lbañez Lucía, Pichler G, Ruiz A, Redon J. Multimorbidity and acute heart failure in internal medicine. Int $\mathrm{J}$ Cardiol. 2017;1:208-15.

13. Pérez-Belmonte LM, Zafra FJ, Pérez-Díaz JM, Platero M, Herrero V, Constán $\mathrm{J}$, et al. Heart failure in Internal Medicine and Cardiology: epidemiological and clinical characteristics. [Abstract 195]. Eur J Intern Med. 2013;24:e16.

14. Kirchhof P, Benussi S, Kotecha D, Ahlsson A, Casadei D, Castella M, et al. ESC Scientific Document Group; 2016 ESC Guidelines for the management of atrial fibrillation developed in collaboration with EACTS. Eur Heart J. 2016;37:2893-962.

15. Piepoli MF, Hoes AW, Agewall S, Albus C, Brotons C, Catapano AL, et al. 2016 European Guidelines on cardiovascular disease prevention in clinical practice: The Sixth Joint Task Force of the European Society of Cardiology and Other Societies on Cardiovascular Disease Prevention in Clinical Practice (constituted by representatives of 10 societies and by invited experts). Developed with the special contribution of the European Association for Cardiovascular Prevention \& Rehabilitation (EACPR). Eur Heart J. 2016;37:2315-81.

16. Ponikowski P, Voors AA, Anker SD, Bueno H, Cleland JG, Coats AJ, et al. 2016 ESC Guidelines for the diagnosis and treatment of acute and chronic heart failure: The Task Force for the diagnosis and treatment of 
acute and chronic heart failure of the European Society of Cardiology (ESC). Developed with the special contribution of the Heart Failure Association (HFA) of the ESC. Eur J Heart Fail. 2016;18:891-975.

17. Matesanz-Fernández M, Monte-Secades R, Íñiguez-Vázquez I, RubalBran D, Guerrero-Sande H, Casariego-Vales E. Characteristics and temporal pattern of the readmissions of patients with multiple hospital admissions in the medical departments of a general hospital. Eur $\mathrm{J}$ Intern Med. 2015;26:776-81.

18. Marques I, Abreu S, Bertão MV, Ferreira B, Ramos RL, Lopes J, et al. Characteristics and outcomes of heart failure hospitalization before implementation of a heart failure clinic: The PRECIC study. Rev Port Cardiol. 2017;36:431-8.

19. Adams KF Jr, Fonarow GC, Emerman CL, LeJemtel TH, Costanzo MR, Abraham WT, et al. Characteristics and outcomes of patients hospitalized for heart failure in the United States: rationale, design, and preliminary observations from the first 100,000 cases in the Acute Decompensated Heart Failure National Registry (ADHERE). Am Heart J. 2005;149:209-16.

20. Fonarow GC, Abraham WT, Albert NM, et al. Impact of evidence-based heart failure therapy use at hospital discharge on treatment rates during follow-up: a report from the organized program to initiate lifesaving treatment in hospitalized patients with heart failure (OPTIMIZE-HF) [abstract]. ([Abstract 4]) J Am Coll Cardiol. 2005;45:345A.

21. Nieminen MS, Brutsaert D, Dickstein K, Drexler H, Follath F, Harjola VP, et al. EuroHeart Failure Survey II (EHFS II): a survey on hospitalized acute heart failure patients: description of population. Eur Heart J. 2006;27:2725-36.

22. Parissis JT, Mantziari L, Kaldoglou N, Ikonomidis I, Nikolaou M, Mebazaa A, et al. Gender-related differences in patients with acute heart failure: management and predictors of in-hospital mortality. Int J Cardiol. 2013;168:185-9.

23. Krittanawong $\mathrm{C}$, Kukin ML. Current management and future directions of heart failure with preserved ejection fraction: a contemporary review. Curr Treat Options Cardiovasc Med. 2018;20:28.

24. Shah SJ, Kitzman DW, Borlaug BA, van Heerebeek L, Zile MR, Kass $\mathrm{DA}$, et al. Phenotype-specific treatment of heart failure with preserved ejection fraction: a multiorgan roadmap. Circulation. 2016;134:73-90.

25. Farmakis D, Parissis J, Lekakis J, Filippatos G. Acute heart failure: epidemiology, risk factors, and prevention. Rev Esp Cardiol. 2015;68:245-8

26. Polonia J, Martins L, Pinto F, Nazare J. Prevalence, awareness, treatment and control of hypertension and salt intake in Portugal: changes over a decade. The PHYSA study. J Hypertens. 2014;32:121121.

27. Rodrigues AP, Gaio V, Kislava I, Graff-Iversen S, Cordeiro E, Silva AC, et al. Prevalência de hipertensão arterial em Portugal: resultados do Primeiro Inquérito Nacional com Exame Físico (INSEF 2015). Instituto Nacional Saúde Dr. Ricardo Jorge. Boletim Epidemiológico. 2017;6:S1114.

28. De Macedo ME, Lima MJ, Silva AO, Alcântara P, Ramalhinho V, Carmona J. Prevalence, awareness, treatment and control of hypertension in Portugal. The PAP study. Rev Port Cardiol. 2007 Jan;26:21-39.

29. González-Juanatey J, Ezquerra EA, Martínez VB, Gutiérrez PC, Nocito AS, Fradera IZ. Heart failure in outpatients: comorbidities and management by different specialists. The EPISERVE Study. Rev Esp Cardiol. 2008;61:611-9.
30. Stewart S, Hart CL, Hole DJ, McMurray JJ. A population-based study of the long-term risks associated with atrial fibrillation: 20-year follow-up of the Renfrew/Paisley study. Am J Med. 2002;113:359-64.

31. O'Connor CM, Abraham WT, Albert NM, Clare R, Gattis Stough W, Gheorghiade $\mathrm{M}$, et al. Predictors of mortality after discharge in patients hospitalized with heart failure: an analysis from the Organized Program to Initiate Lifesaving Treatment in Hospitalized Patients with Heart Failure (OPTIMIZE-HF). Am Heart J. 2008;156:662-73.

32. Braunstein JB, Anderson GF, Gerstenblith G, Weller W, Niefeld M, Herbert R, et al. Noncardiac comorbidity increases preventable hospitalizations and mortality among Medicare beneficiaries with chronic heart failure. J Am Coll Cardiol. 2003;42:1226-33.

33. van Deursen VM, Urso R, Laroche C, Damman K, Dahlström U, Tavazzi $\mathrm{L}$, et al. Co-morbidities in patients with heart failure: an analysis of the European Heart Failure Pilot Survey. Eur J Heart Fail. 2014;16:103-11.

34. Parissis JT, Rafouli-Stergiou P, Mebazaa A, et al. Acute heart failure in patients with diabetes mellitus: clinical characteristics and predictors of in-hospital mortality. Int J Cardiol. 2012;157:108-13.

35. Sarma S, Mentz RJ, Kwasny MJ, Ikonomidis I, Bistola V, Nikolaou M, et al. Association between diabetes mellitus and post-discharge outcomes in patients hospitalized with heart failure: findings from the EVEREST trial. Eur J Heart Fail. 2013;15:194-202.

36. Alimonda $A L$, Núñez J, Núñez E, Husser $O$, Sanchis J, Bodí $V$, et al. Hyperuricemia in acute heart failure. More than a simple spectator? Eur J Intern Med. 2009;20:74-9.

37. Kenchaiah S, Evans JC, Levy D, Wilson PW, Benjamin EJ, Larson MG, et al. Obesity and the risk of heart failure. N Engl J Med. 2002;347:30513.

38. Gupta PP, Fonarow GC, Horwich TB. Obesity and the obesity paradox in heart failure. Can J Cardiol. 2015;31:195-202.

39. Qiu C, Winblad B, Marengoni A, Klarin I, Fastbom J, Fratiglioni L. Heart failure and risk of dementia and Alzheimer disease: a population-based cohort study. Arch Intern Med. 2006;166:1003-8.

40. Rusanen M, Kivipelto M, Levälahti E, Laatikainen T, Tuomilehto J, Soininen $\mathrm{H}$, et al. Heart diseases and long-term risk of dementia and Alzheimer's disease: a population-based CAIDE study. J Alzheimers Dis. 2004;42:183-91.

41. Dodson JA, Truong TT, Towle VR, Kerins G, Chaudhry SI. Cognitive impairment in older adults with heart failure: prevalence, documentation, and impact on outcomes. Am J Med. 2013;126:120-6.

42. Zuccala G, Pedone C, Cesari M, Onder G, Pahor M, Marzetti E, et al. The effects of cognitive impairment on mortality among hospitalized patients with heart failure. Am J Med. 2003;115:97-103.

43. O'Connor CM, Miller AB, Blair JE, Konstam MA, Wedge P, Bahit MC, et al. Causes of death and rehospitalization in patients hospitalized with worsening heart failure and reduced left ventricular ejection fraction: results from Efficacy of Vasopressin Antagonism in Heart Failure Outcome Study with Tolvaptan (EVEREST) program. Am Heart J. 2010;159:841-9.e1.

44. Sharma A, Zhao X, Hammill BG, Hernandez AF, Fonarow GC, Felker $\mathrm{GM}$, et al. Trends in noncardiovascular comorbidities among patients hospitalized for heart failure: insights from the Get With The GuidelinesHeart Failure Registry. Circ Heart Fail. 2018;11:e004646.

45. Almagro P, Cabrera FJ, Diez-Manglano J, Boixeda R, Recio J, Mercade $\mathrm{J}$, et al. Comorbidome and short-term prognosis in hospitalised COPD patients: the ESMI study. Eur Respir J. 2015;46:850-3. 